\title{
Risk factors for the development of acute lung injury in patients with infectious pneumonia
}

\author{
Marija Kojicic ${ }^{1,2}$, Guangxi Li ${ }^{1,3}$, Andrew C Hanson ${ }^{4}$, Kun-Moo Lee ${ }^{1,5}$, Lokendra Thakur $^{1}$, Jayanth Vedre ${ }^{1}$, \\ Adil Ahmed ${ }^{1}$, Larry M Baddour ${ }^{6}$, Jay $\mathrm{H} \mathrm{Ryu}^{1}$ and Ognjen Gajic ${ }^{1 *}$
}

\begin{abstract}
Introduction: Although pneumonia has been identified as the single most common risk factor for acute lung injury (ALI), we have a limited knowledge as to why ALI develops in some patients with pneumonia and not in others. The objective of this study was to determine frequency, risk factors, and outcome of ALI in patients with infectious pneumonia.
\end{abstract}

Methods: A retrospective cohort study of adult patients with microbiologically positive pneumonia, hospitalized at two Mayo Clinic Rochester hospitals between January 1, 2005, and December 31, 2007. In a subsequent nested case-control analysis, we evaluated the differences in prehospital and intrahospital exposures between patients with and without ALI/acute respiratory distress syndrome (ARDS) matched by specific pathogen, isolation site, gender, and closest age in a 1:1 manner.

Results: The study included 596 patients; 365 (61.2\%) were men. The median age was 65 (IQR, 53 to 75) years. In total, 171 patients (28.7\%) were diagnosed with ALI. The occurrence of ALI was less frequent in bacterial ( $n=99$ of $412,24 \%)$ compared with viral ( $n=19$ of 55,35\%), fungal $(n=39$ of 95, 41\%), and mixed isolates pneumonias $(n=$ 14 of 34, 41\%; $P=0.002$ ). After adjusting for baseline severity of illness and comorbidities, patients in whom ALI developed had a markedly increased risk of hospital death $\left(\mathrm{OR}_{\mathrm{adj}} 9.7 ; 95 \% \mathrm{Cl}, 6.0\right.$ to 15.9$)$. In a nested case-control study, presence of shock (OR, 8.9; 95\% Cl, 2.8 to 45.9), inappropriate initial antimicrobial treatment $(\mathrm{OR}, 3.2 ; 95 \% \mathrm{Cl}$, 1.3 to 8.5$)$, and transfusions (OR, 4.8; $95 \% \mathrm{Cl}, 1.5$ to 19.6$)$ independently predicted ALI development.

Conclusions: The development of ALI among patients hospitalized with infectious pneumonia varied among pulmonary pathogens and was associated with increased mortality. Inappropriate initial antimicrobial treatment and transfusion predict the development of ALI independent of pathogen.

\section{Introduction}

Despite recent improvements in supportive treatment, acute lung injury (ALI) remains a devastating syndrome, with pneumonia as the most common predisposing condition [1]. Although recent data demonstrated temporal improvement in survival, the mortality in ALI patients still remains high $[2,3]$.

Because therapeutic options are limited and the majority of intervention strategies are focused on supportive treatment, emphasis has been placed on identifying patients who are at higher risk for ALI $[4,5]$. Patients

\footnotetext{
* Correspondence: gajic.ognjen@mayo.edu

${ }^{1}$ The Division of Pulmonary and Critical Care Medicine, Department of Medicine, Mayo Clinic College of Medicine, 200 First Street SW, Rochester, MN 55905, USA

Full list of author information is available at the end of the article
}

with ALI represent a heterogeneous group of patients with regard to predisposing conditions [6] that differ in pathophysiologic changes $[7,8]$, clinical and radiologic [9] characteristics, as well as treatment options $[10,11]$, but the data on specific risk factors in subsets of patients according to predisposing causes are limited. Although sepsis, particularly pulmonary in origin, is the most common underlying risk factor for ALI, in only a small proportion of hospitalized patients with pneumonia does the complication develop $(<10 \%)$ [4]. Defining risk factors associated with the development of ALI in patients with infectious pneumonia is challenging because virulence factors of different pathogens have been implicated in causing lung damage $[12,13]$. In patients with pneumonia, the relation between ALI and specific pathogens has been described mainly in case 
series and case reports of acute respiratory distress syndrome (ARDS) in patients with Legionella and certain types of viral and fungal pneumonia, suggesting that some pathogens are particularly prone to induce lung injury. A recent study of critically ill patients demonstrated that pulmonary infection is associated with a higher risk of developing ARDS, as compared with infections at nonpulmonary sites [14]. Systematic data regarding occurrence, risk factors, and outcome of ALI/ ARDS in patients with infectious pneumonia are lacking.

The objective of the present study was to determine the frequency and outcome of ALI in a retrospective cohort of hospitalized patients with microbiology-proven pneumonia and to identify prehospital and hospital exposures that may predict the development of ALI, independent of pathogen.

\section{Materials and methods}

We used validated queries of the Mayo Clinic electronic medical record database (Mayo Clinic Life Sciences System) $[15,16]$ to identify consecutive patients with microbiologically positive pneumonia who were hospitalized at the two Mayo Clinic Rochester hospitals between January 1, 2005, and December 31, 2007. The Institutional Review Board approved the study protocol and waived the need for informed consent in this observational study. To be included in the study, patients had to be at least 18 years of age and have a diagnosis of pneumonia with identified pathogens according to the International Classification of Diseases, 9th Revision, Clinical Modification (ICD-9-CM) (ICD codes 480.0-480.8, 481-482.89, $483-484.8,487.0,114.0,115.5,116.0$ and 136.3). If a patient had more than one episode that met inclusion criteria, only the first episode was included. Electronic medical records, including portable digital chest radiographs and microbiology reports, were independently reviewed to confirm the diagnosis of pneumonia and pathogen isolation. Pneumonia was defined as a new or progressive infiltrate as seen on a chest radiograph or CT scan along with a high clinical suspicion of pneumonia, defined with at least one of the following: fever (> $38^{\circ} \mathrm{C}$ or $\left.>100.4^{\circ} \mathrm{F}\right)$, leukopenia $\left(<4,000 \mathrm{WBC} / \mathrm{mm}^{3}\right)$ or leukocytosis $\left(>12,000 \mathrm{WBC} / \mathrm{mm}^{3}\right)$, altered mental status with no other recognized cause (for adults older than 70 years), and at least two of the following: (a) new onset of purulent sputum, or change in character of sputum, or increased respiratory secretions, or increased suctioning requirements, (b) new onset or worsening cough, or dyspnea, or tachypnea, (c) rales or bronchial breath sounds, and (d) worsening gas exchange, increased oxygen requirements, or increased ventilation demand $[17,18]$. The onset of pneumonia (the time of diagnosis of pneumonia) was defined by the first recorded time of any criterion when these criteria were met.

\section{Microbiological etiology}

Patients were included if one or more respiratory pathogens were recovered from: (a) an uncontaminated specimen (blood, pleural fluid, transtracheal aspirate, transthoracic aspirate, or surgical lung biopsy specimen); (b) positive serology defined as elevated immunoglobulin M (IgM) antibodies or fourfold increases in IgG antibody titers; (c) positive urinary antigen test; (d) positive polymerase chain reaction (PCR); (e) semiquantitative cultures of a lower respiratory tract sample (endotracheal aspirate, bronchoalveolar lavage (BAL), or protected specimen brush); (f) or expectorated sputum culture.

We identified ALI patients with a validated electronic syndrome surveillance tool (ALI "sniffer") that was developed for early recognition of patients meeting inclusion criteria for ARDS-net trials. The negative predictive value $99.6 \%$ (95\% CI, 99.3 to 99.8 ) of the electronic alert had been determined in a previous study against the gold standard of prospective assessment by trained intensivist researchers, blinded to the ALI electronic alert. The details of the ALI electronic alert have been previously published [16]. All patients with a positive ALI "sniffer" were reassessed and ALI diagnosed by an independent review of portable chest radiographs, arterial blood gases, and hemodynamic parameters based on American/European consensus conference definition [19]. For adequate interpretation of radiologic studies in the diagnosis of ALI, the abstractors reviewed a structured ALI tutorial before study onset. Interrater reliability for diagnosing ALI was assessed in previous studies (kappa value of 0.8) [20]. The timing of ARDS was determined by the first recorded time of either criterion when both criteria $\left(\mathrm{PaO}_{2} / \mathrm{FIO}_{2}\right.$, bilateral infiltrates) were met.

To identify the risk factors for ALI development, in a subsequent nested case-control study, patients who developed ALI more than 6 hours after pneumonia onset were matched to patients at risk who did not develop ALI, based on specific pathogen, isolation site, gender, and closest age in a 1:1 matching. If an appropriate control was not found for a specific pathogen, matching was for the same genus, family, and finally pathogen group (G-, G+, atypical bacteria, viruses, and fungi). Patients with coinfections were matched to appropriate controls in the same fashion (all pathogens were matched). Because preliminary data suggested increased risk of ALI among Pneumocystis jirovecii pneumonia, these cases were matched to specific pathogen, regardless of coinfection. The matching was conservative to provide as perfect as possible matches. Among 171 cases of ALI, 118 were diagnosed with ALI more than 6 hours after pneumonia onset, of whom 112 were matched according these criteria. We extracted data 
from the preexisting hospital electronic database, which included integrated microbiologic and susceptibility results, vital signs as well as laboratory parameters, comorbidities, and use of medications. Risk factors were compared between patients who developed ALI and matched controls. For quality assurance, we performed random checks of electronic database entries. Standard definitions were used for shock [21], inappropriate antimicrobial treatment [22], and transfusions [23]. We used the Pneumonia severity index (PSI) [24] to assess baseline severity of illness and the Charlson score [25] as a measure of comorbidities. Arterial oxygen saturation measured by pulse oximetry $\left(\mathrm{SpO}_{2}\right)$ was recorded if there was a delay in obtaining arterial blood gas analysis, and the $\mathrm{SpO}_{2} / \mathrm{FIO}_{2}$ ratio was used to substitute $\mathrm{PaO}_{2} /$ $\mathrm{FIO}_{2}$ ratio $\left(\mathrm{SpO}_{2} / \mathrm{FIO}_{2}<315\right.$ corresponds to $\mathrm{PaO}_{2} / \mathrm{FIO}_{2}$ <300) [26]. To assure similar exposure time to possible risk factors between cases and controls, the exposure time for each control was matched to the exposure time of the corresponding case. That means that data on possible intrahospital exposures of cases were collected from onset of pneumonia to onset of ALI, whereas in controls, data were tabulated for the same number of hours subsequent to the onset of pneumonia.

We excluded patients with pneumonectomy and ventilator-associated pneumonia (VAP). VAP patients were excluded to eliminate the possibility of including patients with pneumonia complicating ALI and to limit effect-cause bias. Patients with potentially contaminated blood culture (bacteremia cases with a single positive blood culture of coagulase-negative staphylococci) were also excluded from the analysis.

\section{Statistical analysis}

Continuous variables were compared by using the Student $t$ test for normally distributed variables and the Wilcoxon rank-sum test for nonnormally distributed variables. The $\chi^{2}$ or Fisher exact test was used to compare categoric variables. In a retrospective cohort of pneumonia patients, the association between pathogens and ALI occurrence, and ALI and hospital mortality was assessed in univariate followed by multivariate logistic regression analysis, after adjusting for baseline severity of illness. In a subsequent nested case-control study of 112 ALI cases and 112 matched controls, paired parametric and nonparametric testing were used as appropriate, followed by a conditional logistic regression to investigate the relation between ALI and specific baseline characteristics and in-hospital exposures. Selection of the variables for a conditional logistic regression model was done, considering both clinical plausibility, and statistical criteria (significance, colinearity, and interaction). All $P$ values of $<0.05$ were considered to indicate statistical significance. SAS statistical software

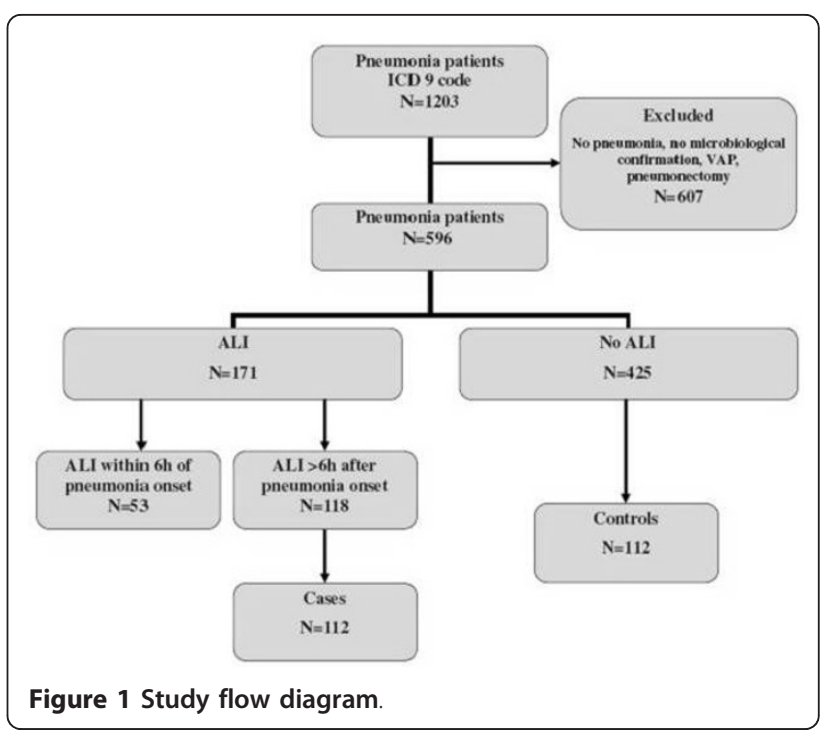

(SAS version 9; SAS Institute, Inc., Cary, NC, USA) was used for statistical analysis.

\section{Results}

Figure 1 shows the flow of study participants. The cohort included 596 patients; 365 (61.2\%) were men. The median age was 65 (interquartile range (IQR), 53 to $75)$ years. The etiology of pneumonia was mostly bacterial $(n=412 ; 69 \%)$, followed by fungal $(n=95 ; 16 \%)$, viral $(n=55 ; 9 \%)$, and mixed pathogens $(n=34 ; 6 \%)$. Co-infections were present in $131(22 \%)$ cases. The pathogens were most commonly isolated from sputum in $206(28.2 \%)$, in tracheal aspirate $151(20.6 \%)$, in bronchoalveolar lavage (BAL) fluid $126(17.3 \%)$, in blood 92 (12.6\%), and in bronchial washings 46 (6.3\%).

Baseline characteristics of patients are presented in Table 1. One hundred and seventy-one patients (28.7\%) were diagnosed with ALI. ALI less commonly occurred in patients with community-acquired pneumonia (CAP) ( $n=61 ; 21.8 \%)$ compared with those with healthcareassociated (HCAP) $(n=53 ; 31.6 \% ; P=0.02)$ and hospital-acquired pneumonias (HAP) $(n=57,38.5 \%$;

Table 1 Baseline characteristics of the cohort

\begin{tabular}{ll}
\hline & $\boldsymbol{N}=\mathbf{5 9 6}$ \\
\hline Age, median (IQR) & $64.5(53-75)$ \\
Male gender, $n(\%)$ & $365(61)$ \\
Pneumonia severity index score, median (IQR) & $119(94-146)$ \\
Charlson comorbidity score, median (IQR) & $2(1-4)$ \\
Pneumonia type, $n(\%)$ & \\
$\quad$ CAP & $280(47)$ \\
$\quad$ HCAP & $168(28)$ \\
HAP & $148(25)$ \\
\hline
\end{tabular}

CAP, community-acquired pneumonia; HAP, hospital-acquired pneumonia; HCAP, healthcare-associated pneumonia; $I Q R$, interquartile range. 
$P<0.001)$. Among 448 patients who had evidence of pneumonia at the time of hospital admission, 43 (9.6\%) presented with ALI on admission, of whom 21 (49\%) were transferred from another hospital; in the remainder, the median time to development of ALI was 2 (IQR, 1 to 3 ) days.

The occurrence of ALI was less frequent in bacterial pneumonias $(n=99$ of $412 ; 24 \%)$ compared with viral ( $n=19$ of $55 ; 35 \%)$, fungal $(n=39$ of $95 ; 41 \%)$, and mixed isolates pneumonias $(n=14$ of $34 ; 41 \%)(P=$ 0.002). Figure 2 displays the frequency of ALI according to the most common pathogens. Similar results were obtained when coinfections were excluded from the analysis. When the analysis was restricted to bacteremic patients, Gram-positive and Gram-negative bacterial infections had a similar frequency of ALI (20\% versus $15 \% ; \mathrm{p}=0.75)$. All patients diagnosed with respiratory syncytial virus (RSV) pneumonia (four of four) developed ALI. Pneumonia due to Pneumocystis jiroveci and Blastomyces species was associated with increased risks of ALI when compared to Streptococcus pneumoniae, the most common cause of pneumonia, in both univariate (OR, 3.35; 95\% CI, 1.5 to 7.61; OR, 4.41; 95\% CI, 1.1 to 19.4, respectively) and multivariate analyses (OR, 3.8; 95\% CI, 1.65 to 8.93 ; OR, 5.6; $95 \%$ CI, 1.3 to 26.2 ; respectively), after adjusting for baseline severity of illness (pneumonia severity index). Patients who developed ALI had a markedly increased risk of hospital death in both univariate $\left(\mathrm{OR}_{\text {adj }} 9.2\right.$; $95 \% \mathrm{CI}, 5.8$ to 14.8$)$ and multivariate analysis after adjusting for baseline severity of

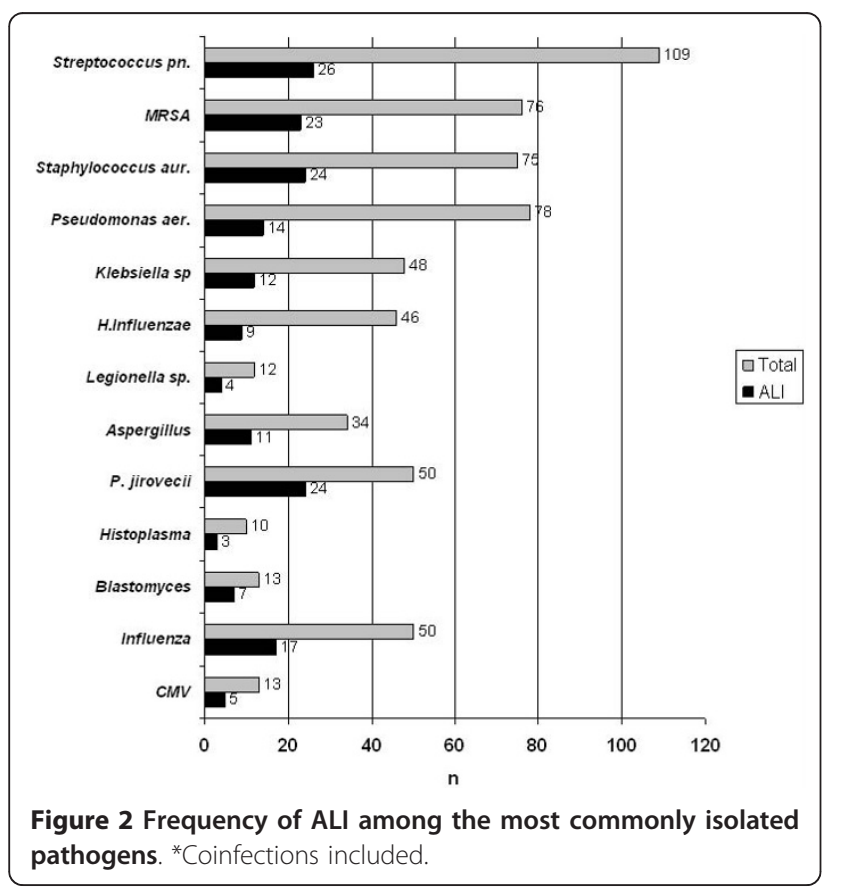

illness and comorbidities (Charlson score) $\left(\mathrm{OR}_{\text {adj }}\right.$ 9.7; 95\% CI, 6.0 to 15.9 ).

The association between previously proposed risk factors for the development of ALI was examined in 112 patients who had no ALI at the time pneumonia was diagnosed and who were matched by specific pathogen, age, and gender. The characteristics of ALI cases and controls are presented in Table 2. Patient groups were similar in terms of comorbidities expressed as cumulative Charlson score. No difference was found in frequency of diabetes between cases and controls. Patients who developed ALI were more likely to present with bilateral infiltrates. Fifty-one patients $(45.5 \%)$ that presented with unilateral infiltrate later progressed to ALI. ALI cases had lower $\mathrm{SaO}_{2} / \mathrm{FiO}_{2}$ at the baseline and higher baseline pneumonia severity index. Most of the patients with RSV and PCP infections were immunosuppressed (30 of 32). The median time to any antibiotic administration was similar in cases and controls, but inappropriate initial antimicrobial treatment was associated with increased risk of ALI (Table 2). The transfusion of fresh frozen plasma, platelets, and red blood cells was associated with ALI development.

When adjusted for baseline imbalances (shock, $\mathrm{SpO}_{2} /$ $\mathrm{FiO}_{2}$, type of pneumonia) in a conditional logistic regression analysis, inappropriate antimicrobial treatment (OR, 3.2; 95\% CI, 1.3 to 8.5) and transfusions (OR, 4.8 ; $95 \% \mathrm{CI}, 1.5$ to 19.6$)$ were independently associated with the development of ALI (Table 3). The results were similar after adjustment for PSI (as a composite measure of baseline severity of illness) (Table 4).

Patients who developed ALI were more likely to be mechanically ventilated, had longer hospital length of stay, and had a markedly increased risk of hospital death (Additional file 1). In a post hoc analysis we explored the association between the prehospital use of certain medications (statins, ACE inhibitors, and antiplatelet drugs) that were found to modify development of ALI in previous studies. When adjusted for adequate antibiotics, transfusion, and PSI in conditional logistic regression analysis, the use of a statin was associated with a decreased risk of ALI (OR, 0.36; 95\% CI, 0.14 to 0.92).

\section{Discussion}

The results of this study suggest that ALI is common in hospitalized pneumonia patients with positive microbiologic diagnosis. In addition, patients with bacterial pneumonia had lower rates of ALI compared with those with fungal, viral, and mixed infections. When controlled for age, gender, and specific pathogen, independent predictors of ALI in pneumonia patients are baseline severity of illness, inappropriate initial antimicrobial treatment, and transfusion. 
Table 2 Univariate analysis of baseline characteristics and interventions in ALI cases and matched controls

\begin{tabular}{|c|c|c|c|c|}
\hline & $\begin{array}{l}\text { ALI cases } \\
n=112\end{array}$ & $\begin{array}{l}\text { Controls } \\
n=112\end{array}$ & Odds ratio & $P$ value \\
\hline \multicolumn{5}{|l|}{ Baseline characteristics } \\
\hline $\begin{array}{l}\text { Age (years) } \\
\text { Median (IQR) }\end{array}$ & $\begin{array}{l}64.5 \\
(53.5-72.0)\end{array}$ & $\begin{array}{l}62.0 \\
(53.0-71.5)\end{array}$ & $1.00(0.98-1.03)$ & 0.65 \\
\hline $\begin{array}{l}\text { Male gender } \\
n(\%)\end{array}$ & $56(50)$ & $61(55)$ & $1.43(0.68-3.3)$ & 0.52 \\
\hline $\begin{array}{l}\text { BMI } \\
\text { Median (IQR) }\end{array}$ & $26.7(24.07-31.05)$ & $\begin{array}{l}26.4 \\
(21.9-30.4)\end{array}$ & $1.00(0.99-1.01)$ & 0.48 \\
\hline $\begin{array}{l}\text { Ever smoker } \\
n(\%)\end{array}$ & $66(59)$ & $52(46)$ & $1.24(0.96-1.65)$ & 0.07 \\
\hline $\begin{array}{l}\text { Alcohol abuse } \\
n(\%)\end{array}$ & $13(12)$ & $9(8)$ & $1.28(0.74-1.93)$ & 0.37 \\
\hline Pneumonia type & & & & $0.007^{\mathrm{a}}$ \\
\hline \multicolumn{5}{|l|}{$n(\%)$} \\
\hline CAP & $33(29.5)$ & $55(49)$ & $0.32(0.15-0.63)$ & \\
\hline HCAP & $33(29.5)$ & $29(26)$ & $1.22(0.66-2.27)$ & \\
\hline HAP & $46(41)$ & $28(25)$ & $2.10(1.19-3.86)$ & \\
\hline $\begin{array}{l}\text { Charlson score } \\
\text { Median (IQR) }\end{array}$ & $3(2-4)$ & $2(1-4)$ & $1.0(0.88-1.14)$ & 0.26 \\
\hline Aspiration n (\%) & $8(7.1)$ & $4(3.6)$ & $1.84(0.63-6.55)$ & 0.25 \\
\hline Diabetes $n(\%)$ & $25(22)$ & $33(29)$ & $0.71(0.39-1.26)$ & 0.24 \\
\hline $\begin{array}{l}\text { Immunosuppression } \\
n(\%)\end{array}$ & $52(46.4)$ & $50(44.6)$ & $1.13(0.54-2.36)$ & 0.73 \\
\hline $\begin{array}{l}\text { Pneumonia severity index score } \\
\text { Median (IQR) }\end{array}$ & $115(92-142)$ & $\begin{array}{l}101 \\
(76-119)\end{array}$ & $1.02(1.01-1.03)$ & $<0.001^{\mathrm{a}}$ \\
\hline Shock $n(\%)$ & $47(42)$ & $9(8)$ & $16.3(5.47-79.04)$ & $<0.001^{a}$ \\
\hline $\begin{array}{l}\text { Respiratory rate } \\
\text { Median (IQR) }\end{array}$ & $23(20-28)$ & $20(18-24)$ & $1.04(1.00-1.08)$ & 0.05 \\
\hline $\begin{array}{l}\mathrm{SaO}_{2} / \mathrm{FiO}_{2} \\
\text { Median (IQR) }\end{array}$ & $\begin{array}{l}236 \\
(107-336)\end{array}$ & $\begin{array}{l}336 \\
(247-448)\end{array}$ & $0.995(0.993-0.997$ & $<0.001^{\mathrm{a}}$ \\
\hline $\begin{array}{l}\text { Bilateral infiltrates } \\
n(\%)\end{array}$ & $61(54.5)$ & $31(38.2)$ & $3.67(1.92-7.61)$ & $<0.001^{\mathrm{a}}$ \\
\hline $\begin{array}{l}\text { Pleural effusion } \\
n(\%)\end{array}$ & $23(20.5)$ & $17(15.4)$ & $1.34(0.68-2.69)$ & 0.38 \\
\hline \multicolumn{5}{|l|}{ Interventions } \\
\hline $\begin{array}{l}\text { Time to antibiotics (hours) } \\
\text { Median (IQR) }\end{array}$ & $0(0-9)$ & $0(0-3)$ & $1.00(0.99-1.02)$ & 0.11 \\
\hline $\begin{array}{l}\text { Appropriate initial antimicrobial treatment } \\
n(\%)\end{array}$ & $62(55.4)$ & $85(75.9)$ & $0.29(0.13-0.58)$ & $<0.001^{a}$ \\
\hline $\begin{array}{l}\text { Any transfusion } \\
n(\%)\end{array}$ & $38(33.9)$ & $15(13.4)$ & $4.53(2.08-11.59)$ & $<0.001^{\mathrm{a}}$ \\
\hline Platelets & $15(13.4)$ & $4(3.6)$ & $6.50(1.47-59.33)$ & $0.0098^{a}$ \\
\hline Red blood cells & $31(27.7)$ & $13(11.6)$ & $4.0(1.59-11.96)$ & $0.002^{a}$ \\
\hline Fresh frozen plasma & $10(8.9)$ & $1(0.9)$ & & $0.008^{a}$ \\
\hline $\begin{array}{l}\text { Corticosteroids systemic } \\
n(\%)\end{array}$ & $48(42.9)$ & $51(45.5)$ & $0.89(0.51-1.55)$ & 0.67 \\
\hline $\begin{array}{l}\text { Mechanical ventilation } \\
n(\%)\end{array}$ & $95(85)$ & $24(21)$ & $29.4(10.2-141.17)$ & $<0.001^{a}$ \\
\hline Invasive & $80(71)$ & $19(17)$ & $18.36(7.24-66.69)$ & \\
\hline Noninvasive & $15(14)$ & $5(4)$ & $2.83(1.13-8.25)$ & \\
\hline
\end{tabular}

$\mathrm{BMI}$, Body mass index; CAP, community-acquired pneumonia; HAP, hospital-acquired pneumonia; HCAP, healthcare-associated pneumonia; IQR, interquartile range. ${ }^{\text {a }}$

a- statistically significant 
Table 3 Conditional regression analysis of ALI risk factors

\begin{tabular}{lll}
\hline & OR & $\mathbf{9 5 \% ~ C l}$ \\
\hline Shock & 8.9 & $2.8-45.9$ \\
171717 & 0.996 & $0.993-0.999$ \\
Inappropriate initial antimicrobial treatment & 3.2 & $1.3-8.5$ \\
Any transfusion & 4.8 & $1.5-19.6$ \\
HAP & 1.9 & $0.8-4.5$ \\
\hline
\end{tabular}

HAP, hospital-acquired pneumonia.

ALI rates in our study were higher compared with a previous study of hospitalized patients with clinically defined pneumonia by Ferguson and colleagues (10\%) [4]. This could be due to the inclusion, in our study, of only patients with a high clinical suspicion of pneumonia and identified isolates, which has been described in fewer than $50 \%$ of hospitalized patients with pneumonia [27]. In addition, most of our patients had an infectious agent isolated from lower respiratory tract secretions, indicating that this population probably represents a group of more severely ill patients. A recent report of infection-related ARDS in patients with sepsis, pneumonia, and bacteremia yielded results similar to ours [14].

In our study, the main causes of pneumonia were $S$. aureus (with high percentage of MRSA), S. pneumoniae and Pseudomonas aeruginosa. Similar results were obtained by Kollef et al. [28]. Among the most common pathogens, no difference in the rates of ALI was found. We observed a higher proportion of ALI occurrence in patients with less common infections due to fungal and viral respiratory pathogens. The higher rate of ALI among these pathogen groups likely relates to $P$. jiroveci, and specific endemic fungi, including Blastomyces species and viral infections (RSV, cytomegalovirus). Possible explanations for this higher risk include delayed antimicrobial treatment, as these pathogens are often not treated with initial empiric antimicrobial coverage, as well as baseline characteristics of the patients, because these infections more commonly occur in those who are immunocompromised. Progression to ALI is likely a result of a complex interaction of patient immune status and specific pathogen [29]. Conversely, when adjusted for a specific pathogen, immunosupression did not influence progression to ALI. However, these results must be interpreted with caution because matching by specific pathogen is similar to matching by immune status or

Table 4 Conditional regression analysis of ALI risk factors

\begin{tabular}{lll}
\hline & OR & $\mathbf{9 5 \%} \mathbf{C l}$ \\
\hline PSI & 1.01 & $1.00-1.03$ \\
Inappropriate initial antimicrobial treatment & 3.1 & $1.5-7.0$ \\
Any transfusion & 3.2 & $1.3-8.8$ \\
HAP & 1.8 & $0.9-3.8$ \\
\hline
\end{tabular}

HAP, hospital-acquired pneumonia; PSI, pneumonia severity index. other baseline risk factors for these pathogens, which precludes analyzing the significance of these risk factors for developing ALI. Unfortunately, our study design does not allow further assessment of independent effects of a pathogen on risk for ALI development. Although numerous reports exist of Legionella pneumoniainduced ARDS, our study failed to confirm an increased risk of ALI in these patients. It is possible that early initiation of empiric antimicrobial coverage for atypical bacteria, as proposed in current pneumonia guidelines, has reduced this devastating complication in patients with Legionella pneumonia. We observed no case of ALI in the course of pneumonia caused by other "atypical" bacteria.

Several studies have shown that ALI is rarely present at the time of hospitalization and usually develops in hours to days after hospital admission [4,30]. The evolution of ALI could be influenced by both baseline characteristics of the patients (first hit) as well as a variety of intrahospital exposures (second hit) [31]. Certain prehospital exposures (alcohol, smoking) [32,33], medical errors (delayed shock resuscitation, delayed antibiotic treatment) [30], and iatrogenic exposures (plasma transfusion from alloimmunized donors, gastric aspiration, certain chemotherapeutic drugs) $[23,34,35]$ have all been associated with development of ALI in hospitalized patients. Similar to the results of other studies [35], we observed higher baseline severity of illness among ALI cases. Considering baseline characteristics, patients with ALI were more often smokers, although statistical difference was not reached. This could be because we used patients' histories to obtain information on smoking. In a recent study by Hsieh [36], serum and urine nicotine metabolites identified considerably more active smokers than did smoking history. Active and passive cigarette smoking was found to be associated with ALI after severe blunt trauma, when a biomarker of tobacco smoking was used to assess smoking history [37]. Unlike several other studies $[32,38]$, the history of alcohol abuse did not influence the risk of ALI. In addition, although the majority of studies implicated diabetes to have a protective role $[39,40]$, no difference in number of diabetics was found between the cases and controls in our study.

The highest percentage of ALI was found among patients with healthcare-associated pneumonia (HCAP) and hospital-acquired pneumonia (HAP), suggesting that health-care-related exposures could have contributed to the development of ALI. When matched for age, gender, and pathogen characteristics, and adjusted for baseline severity of illness, the major interventions that were associated with an increased risk of ALI were transfusions and inappropriate initial antimicrobial therapy. Previous studies demonstrated an increased risk of 
ALI in patients with delayed treatment of infection [30]. The time of antibiotic initiation did not influence ALI development in our study, as most patients received antibiotics in the emergency department or immediately after admission; however, ALI was associated with inappropriate initial antimicrobial therapy. In patients with pneumonia, inappropriate initial antibiotic treatment noticeably increases the risk of hospital death [41,42]. The failure to provide adequate antibiotic treatments is more likely in HCAP and HAP, as Gram-negative bacteria and $S$. aureus are major pathogens in these patients [28]. In addition to antimicrobial resistance [41], it seems that patients with HCAP are often not empirically treated for these organisms, resulting in suboptimal antibiotic therapy and increased mortality [43]. Although shock was clearly associated with ALI development, the association of delayed goal-directed resuscitation could not be examined because of a relatively low number of shock patients among controls. The observed association between transfusion and lung injury has been demonstrated in number of studies $[40,44,45]$. The observed association between the use of statins and the decreased risk of ALI is consistent with the recent report by O'Neal et al. [46]. Contrary to a previous report in a population-based cohort of nonselected patients at risk of ALI [47], the use of antiplatelet agents in patients with infectious pneumonia was not associated with decreased risk of ALI.

Severe pneumonia is associated with high rates of morbidity and mortality [48-51]. The majority of these studies failed to account for ALI as well as its role in the course of pneumonia and patient outcomes. Our work demonstrated that the development of ALI is independently associated with increased mortality after adjusting for baseline severity of illness and comorbidities. This is particularly important because multiple factors influence ALI development and are potential targets for preventing this devastating syndrome.

Our study has several limitations. First, enrollment was limited to microbiologically proven pneumonia. Because the majority of patients with pneumonia do not undergo any microbial testing, some patients with pneumonia were excluded and may have biased our study population to more severe cases that underwent such evaluation. Diagnosis of atypical pneumonia is difficult because of the fastidious nature of atypical organisms; the sensitivity of cultures is low, serologic assays are poorly standardized [52], and PCR is not generally available [27]. Because only semiquantitative analysis of lower respiratory secretions were available, differentiation between microbiologically definite and probable pneumonia was not possible in all patients. Conversely, because ALI/ARDS also has noninfectious etiologies (aspiration, organizing pneumonia, transfusion-induced lung injury (TRALI), acute eosinophilic pneumonia, diffuse alveolar hemorrhage, and other interstitial lung diseases), we believe that isolation of a microbiologic agent strengthened the diagnosis of infectious pneumonia and prevented the inclusion of noninfectious lung diseases that might have been included by using only the clinical definition.

Second, because we matched by pathogen, we could not properly examine the influence of specific pathogen and immune status on ALI development. It is likely that the results would be different for specific viral (RSV, $\mathrm{CMV}$ ) or fungal (PCP) pathogens, but limited control data precludes the analysis (because clinicians rarely test immunocompetent patients for these pathogens). Conversely, matching by specific pathogen supports the findings that inappropriate antimicrobial treatment is an independent predictor of ALI and not just a marker of having an atypical pathogen.

Third, differentiation between severe bilateral pneumonia and ALI/ARDS may be challenging. Sensitivity and specificity of clinical assessment compared with a pathologic finding of diffuse alveolar damage (DAD) was found to be poor, with the weakest correlation in pneumonia patients [53].

Fourth, we used the pneumonia severity index as a composite measure of baseline severity of illness in all patients. The PSI has been validated in CAP and HCAP but not HAP patients. However, the results were similar when adjusted for baseline imbalances (shock, $\mathrm{SpO}_{2} /$ $\mathrm{FiO}_{2}$ ) instead of PSI.

Finally, a limitation of our study is inherent in its retrospective design.

\section{Conclusions}

In conclusion, to our knowledge, this is the first study to assess the relation between ALI and specific respiratory pathogens isolated from patients with pneumonia. The results show that patients with confirmed infectious pneumonia are at a high risk of ALI, especially those with certain types of fungal and viral pneumonias. No difference was found in the occurrence of ALI among the most common bacterial pathogens, suggesting other possible mechanisms that may promote the development of ALI, aside from pathogen characteristics. Potentially modifiable health-care delivery factors such as antibiotic therapy and transfusion pose significant risk and provide important targets for ALI prevention.

\section{Key messages}

- ALI development is common among hospitalized pneumonia patients with positive microbiology.

- The development of ALI among patients hospitalized with infectious pneumonia varies among pulmonary pathogens and is associated with increased mortality. 
- Inappropriate initial antimicrobial treatment and transfusion of blood products are modifiable independent predictors of ALI development in pneumonia patients.

\section{Additional material}

Additional file 1: Outcomes of ALI cases and matched controls Table describing the differences in hospital length of stay, duration of mechanical ventilation, and hospital mortality between ALI cases and matched controls.

\section{Abbreviations}

ALI: Acute lung injury; APACHE: Acute Physiology and Chronic Health Evaluation; BMI: body mass index; CAP: community-acquired pneumonia; $\mathrm{Cl}$ : confidence interval; ICD-9-CM: International Classification of Diseases: 9th Rev.: Clinical Modification; ICU: intensive care unit; IQR: interquartile range; HCAP: health-care-associated pneumonia; HAP: hospital-acquired pneumonia; OR: odds ratio; PSI: Pneumonia Severity Index score; TRALI: transfusioninduced lung injury.

\section{Acknowledgements}

This publication was made possible by grant number 1 UL1 RR024150 from the National Center for Research Resources (NCRR), a component of the National Institutes of Health, and the NIH Roadmap for Medical Research. Its contents are solely the responsibility of the authors and do not necessarily represent the official view of the NCRR or NIH. Information on NCRR is available at: http://www.ncrr.nih.gov/. Information on Reengineering the Clinical Research Enterprise can be obtained from: http://nihroadmap.nih. gov.

\section{Author details}

${ }^{1}$ The Division of Pulmonary and Critical Care Medicine, Department of Medicine, Mayo Clinic College of Medicine, 200 First Street SW, Rochester, MN 55905, USA. ${ }^{2}$ Urgent Pulmonology Department, The Institute for Pulmonary Diseases of Vojvodina, Institutski put 4, Sremska Kamenica 21204, Serbia. ${ }^{3}$ Department of Pulmonary Medicine, Guang An Men Hospital, China Academy of Chinese Medical Science, 5 BeiXianGe Street, Beijing 100053 China. ${ }^{4}$ The Division of Biostatistics, Department of Health Sciences Research, Mayo Clinic College of Medicine, 200 First Street SW, Rochester, MN 55905, USA. ${ }^{5}$ Department of Anesthesiology, Paik Hospital, College of Medicine, InJe University, Gaegeum 2-dong, Busanjin-gu, Busan 614-735, South Korea. ${ }^{6} T$ The Division of Infectious Diseases, Department of Medicine, Mayo Clinic College of Medicine, 200 First Street SW, Rochester, MN 55905, USA.

\section{Authors' contributions}

Study concept and design, MK and OG; acquisition of data, GL, KML, LT, JV, $A A$, and MK; analysis and interpretation of data, MK, GL, and OG; drafting of the manuscript, MK and OG; critical revision of the manuscript for important intellectual content, LB and JR; statistical analysis, $A H, G L$, and MK.

\section{Competing interests}

The authors declare that they have no competing interests.

Received: 27 August 2011 Revised: 12 February 2012

Accepted: 14 March 2012 Published: 14 March 2012

\section{References}

1. Rubenfeld GD, Herridge MS: Epidemiology and outcomes of acute lung injury. Chest 2007, 131:554-562.

2. Erickson SE, Martin GS, Davis JL, Matthay MA, Eisner MD: Recent trends in acute lung injury mortality: 1996-2005. Crit Care Med 2009, 37:1574-1579.

3. Spragg RG, Bernard GR, Checkley W, Curtis JR, Gajic O, Guyatt G, Hall J, Israel E, Jain M, Needham DM, Randolph AG, Rubenfeld GD, Schoenfeld D, Thompson BT, Ware LB, Young D, Harabin AL: Beyond mortality: future clinical research in acute lung injury. Am J Respir Crit Care Med 2010, 181:1121-1127.

4. Ferguson ND, Frutos-Vivar F, Esteban A, Gordo F, Honrubia T, Penuelas O, Algora A, Garcia G, Bustos A, Rodriguez I: Clinical risk conditions for acute lung injury in the intensive care unit and hospital ward: a prospective observational study. Crit Care 2007, 11:R96.

5. Garber BG, Hebert PC, Yelle JD, Hodder RV, McGowan J: Adult respiratory distress syndrome: a systemic overview of incidence and risk factors. Crit Care Med 1996, 24:687-695.

6. Phua J, Stewart TE, Ferguson ND: Acute respiratory distress syndrome 40 years later: time to revisit its definition. Crit Care Med 2008, 36:2912-2921.

7. Pelosi P, D'Onofrio D, Chiumello D, Paolo S, Chiara G, Capelozzi VL, Barbas CS, Chiaranda M, Gattinoni L: Pulmonary and extrapulmonary acute respiratory distress syndrome are different. Eur Respir J Supp/ 2003, 42:48-56.

8. Hoelz C, Negri EM, Lichtenfels AJ, Concecao GM, Barbas CS, Saldiva PH, Capelozzi VL: Morphometric differences in pulmonary lesions in primary and secondary ARDS: a preliminary study in autopsies. Pathol Res Pract 2001, 197:521-530.

9. Goodman LR, Fumagalli R, Tagliabue P, Tagliabue M, Ferrario M, Gattinoni L, Pesenti A: Adult respiratory distress syndrome due to pulmonary and extrapulmonary causes: CT, clinical, and functional correlations. Radiology 1999, 213:545-552.

10. Lim CM, Jung H, Koh Y, Lee JS, Shim TS, Lee SD, Kim WS, Kim DS, Kim WD: Effect of alveolar recruitment maneuver in early acute respiratory distress syndrome according to antiderecruitment strategy, etiological category of diffuse lung injury, and body position of the patient. Crit Care Med 2003, 31:411-418.

11. Taut FJ, Rippin G, Schenk P, Findlay G, Wurst W, Hafner D, Lewis JF, Seeger W, Gunther A, Spragg RG: A search for subgroups of patients with ARDS who may benefit from surfactant replacement therapy: a pooled analysis of five studies with recombinant surfactant protein-C surfactant (Venticute). Chest 2008, 134:724-732.

12. Bauer TT, Ewig S, Rodloff AC, Muller EE: Acute respiratory distress syndrome and pneumonia: a comprehensive review of clinical data. Clin Infect Dis 2006, 43:748-756.

13. Martin TR: Direct lung injury by bacteria: clarifying the tools of the trade. Crit Care Med 2004, 32:2360-2361.

14. Sheu CC, Gong MN, Zhai R, Bajwa EK, Chen F, Taylor Thompson B, Christiani DC: The influence of infection sites on development and mortality of ARDS. Intensive Care Med 2010, 36:963-970.

15. Li G, Malinchoc M, Cartin-Ceba R, Venkata CV, Kor DJ, Peters SG, Hubmayr RD, Gajic O: Eight-year trend of acute respiratory distress syndrome: a population-based study in Olmsted County, Minnesota. Am J Respir Crit Care Med 2011, 183:59-66.

16. Herasevich V, Yilmaz M, Khan H, Hubmayr RD, Gajic O: Validation of an electronic surveillance system for acute lung injury. Intensive Care Med 2009, 35:1018-1023.

17. Horan TC, Andrus M, Dudeck MA: CDC/NHSN surveillance definition of health care-associated infection and criteria for specific types of infections in the acute care setting. Am J Infect Control 2008, 36:309-332.

18. Bartlett JG, Dowell SF, Mandell LA, File TM Jr, Musher DM, Fine MJ: Practice guidelines for the management of community-acquired pneumonia in adults: Infectious Diseases Society of America. Clin Infect Dis 2000, 31:347-382.

19. Bernard GR, Artigas A, Brigham KL, Carlet J, Falke K, Hudson L, Lamy M, Legall JR, Morris A, Spragg R, Cochin B, Lanken PN, Leeper KV, Marini J, Murray JF, Oppenheimer L, Pesenti A, Reid L, Rinaldo J: The AmericanEuropean Consensus Conference on ARDS: Definitions, mechanisms, relevant outcomes, and clinical trial coordination. Am J Respir Crit Care Med 1994, 149:818-824.

20. Cartin-Ceba R, Kojicic M, Li G, Kor DJ, Poulose J, Herasevich V, Kashyap R, Trillo-Alvarez C, Cabello-Garza J, Hubmayr R, Seferian EG, Gajic O: Epidemiology of critical care syndromes, organ failures and life support interventions in a suburban U.S. community. Chest 2011, 140:1447-1455.

21. Antonelli M, Levy M, Andrews PJ, Chastre J, Hudson LD, Manthous C, Meduri GU, Moreno RP, Putensen C, Stewart T, Torres A: Hemodynamic monitoring in shock and implications for management: International Consensus Conference, Paris, France, 27-28 April 2006. Intensive Care Med 2007, 33:575-590. 
22. Kollef MH, Sherman G, Ward S, Fraser VJ: Inadequate antimicrobial treatment of infections: a risk factor for hospital mortality among critically ill patients. Chest 1999, 115:462-474.

23. Gajic O, Rana R, Winters JL, Yilmaz M, Mendez JL, Rickman OB, O'Byrne MM, Evenson LK, Malinchoc M, DeGoey SR, Afessa B, Hubmayr RD, Moore SB: Transfusion-related acute lung injury in the critically ill: prospective nested case-control study. Am J Respir Crit Care Med 2007, 176:886-891

24. Fine MJ, Auble TE, Yealy DM, Hanusa BH, Weissfeld LA, Singer DE, Coley CM, Marrie TJ, Kapoor WN: A prediction rule to identify low-risk patients with community-acquired pneumonia. N Engl J Med 1997, 336:243-250.

25. Charlson ME, Pompei P, Ales KL, Mackenzie CR: A new method of classifying prognostic comorbidity in longitudinal studies: development and validation. J Chronic Dis 1987, 40:373-383.

26. Rice TW, Wheeler AP, Bernard GR, Hayden DL, Schoenfeld DA, Ware LB: Comparison of the $\mathrm{SpO}_{2} / \mathrm{FIO}_{2}$ ratio and the $\mathrm{PaO}_{2} / \mathrm{FIO}_{2}$ ratio in patients with acute lung injury or ARDS. Chest 2007, 132:410-417.

27. Bartlett JG: Diagnostic test for etiologic agents of community-acquired pneumonia. Infect Dis Clin North Am 2004, 18:809-827.

28. Kollef MH, Shorr A, Tabak YP, Gupta V, Liu LZ, Johannes RS: Epidemiology and outcomes of health-care-associated pneumonia: results from a large US database of culture-positive pneumonia. Chest 2005, 128:3854-3862.

29. Mizgerd JP: Acute lower respiratory tract infection. N Engl J Med 2008, 358:716-727.

30. Iscimen R, Cartin-Ceba R, Yilmaz M, Khan H, Hubmayr RD, Afessa B, Gajic O: Risk factors for the development of acute lung injury in patients with septic shock: an observational cohort study. Crit Care Med 2008, 36:1518-1522.

31. Matthay MA, Zimmerman GA, Esmon C, Bhattacharya J, Coller B, Doerschuk CM, Floros J, Gimbrone MA Jr, Hoffman E, Hubmayr RD, Leppert M, Matalon S, Munford R, Parsons P, Slutsky AS, Tracey K, Ward P, Gail DB, Harabin AL: Future research directions in acute lung injury: summary of a National Heart, Lung, and Blood Institute working group. Am J Respir Crit Care Med 2003, 167:1027-1035.

32. Moss M, Bucher B, Moore FA, Moore EE, Parsons PE: The role of chronic alcohol abuse in the development of acute respiratory distress syndrome in adults. JAMA 1996, 275:50-54.

33. Iribarren C, Jacobs DR Jr, Sidney S, Gross MD, Eisner MD: Cigarette smoking, alcohol consumption, and risk of ARDS: a 15-year cohort study in a managed care setting. Chest 2000, 117:163-168.

34. Reed CR, Glauser FL: Drug-induced noncardiogenic pulmonary edema. Chest 1991, 100:1120-1124.

35. Hudson LD, Milberg JA, Anardi D, Maunder RJ: Clinical risks for development of the acute respiratory distress syndrome. Am J Respir Crit Care Med 1995, 151:293-301.

36. Hsieh SJ, Ware LB, Eisner MD, Yu L, Jacob P, Havel C, Goniewicz ML, Matthay MA, Benowitz NL, Calfee CS: Biomarkers increase detection of active smoking and secondhand smoke exposure in critically ill patients. Crit Care Med 2011, 39:40-45.

37. Calfee CS, Matthay MA, Eisner MD, Benowitz N, Call M, Pittet JF, Cohen MJ: Active and passive cigarette smoking and acute lung injury after severe blunt trauma. Am J Respir Crit Care Med 2011, 183:1660-1665.

38. Thakur L, Kojicic M, Thakur SJ, Pieper MS, Kashyap R, Trillo-Alvarez CA, Javier F, Cartin-Ceba R, Gajic O: Alcohol consumption and development of acute respiratory distress syndrome: a population-based study. Int $J$ Environ Res Public Health 2009, 6:2426-2435.

39. Moss M, Guidot DM, Steinberg KP, Duhon GF, Treece P, Wolken R, Hudson LD, Parsons PE: Diabetic patients have a decreased incidence of acute respiratory distress syndrome. Crit Care Med 2000, 28:2187-2192.

40. Gong MN, Thompson BT, Williams P, Pothier L, Boyce PD, Christiani DC: Clinical predictors of and mortality in acute respiratory distress syndrome: potential role of red cell transfusion. Crit Care Med 2005, 33:1191-1198.

41. Torres A, Ewig S, Lode H, Carlet J: Defining, treating and preventing hospital acquired pneumonia: European perspective. Intensive Care Med 2009, 35:9-29

42. Mandell LA, Wunderink RG, Anzueto A, Bartlett JG, Campbell GD, Dean NC, Dowell SF, File TM Jr, Musher DM, Niederman MS, Torres A, Whitney CG Infectious Diseases Society of America/American Thoracic Society consensus guidelines on the management of community-acquired pneumonia in adults. Clin Infect Dis 2007, 44:27-72.
43. Venditti M, Falcone M, Corrao S, Licata G, Serra P: Outcomes of patients hospitalized with community-acquired, health care-associated, and hospital-acquired pneumonia. Ann Intern Med 2009, 150:19-26.

44. Zilberberg MD, Carter C, Lefebvre P, Raut M, Vekeman F, Duh MS, Shorr AF: Red blood cell transfusions and the risk of acute respiratory distress syndrome among the critically ill: a cohort study. Crit Care 2007, 11:R63.

45. Khan H, Belsher J, Yilmaz M, Afessa B, Winters JL, Moore SB, Hubmayr RD, Gajic O: Fresh-frozen plasma and platelet transfusions are associated with development of acute lung injury in critically ill medical patients. Chest 2007, 131:1308-1314.

46. O'Neal HR Jr, Koyama T, Koehler EA, Siew E, Curtis BR, Fremont RD, May AK, Bernard GR, Ware LB: Prehospital statin and aspirin use and the prevalence of severe sepsis and acute lung injury/acute respiratory distress syndrome. Crit Care Med 2011, 39:1343-1350.

47. Erlich JM, Talmor DS, Cartin-Ceba R, Gajic O, Kor DJ: Pre-hospitalization anti-platelet therapy is associated with a reduced incidence of acute lung injury: a population-based cohort study. Chest 2011, 139:289-95.

48. Yoshimoto A, Nakamura H, Fujimura M, Nakao S: Severe communityacquired pneumonia in an intensive care unit: risk factors for mortality. Intern Med 2005, 44:710-716.

49. Restrepo MI, Mortensen EM, Velez JA, Frei C, Anzueto A: A comparative study of community-acquired pneumonia patients admitted to the ward and the ICU. Chest 2008, 133:610-617.

50. Fine MJ, Smith MA, Carson CA, Mutha SS, Sankey SS, Weissfeld LA, Kapoor WN: Prognosis and outcomes of patients with communityacquired pneumonia: a meta-analysis. JAMA 1996, 275:134-141.

51. Marrie TJ, Shariatzadeh MR: Community-acquired pneumonia requiring admission to an intensive care unit: a descriptive study. Medicine (Baltimore) 2007, 86:103-111.

52. Littman AJ, Jackson LA, White E, Thornquist MD, Gaydos CA, Vaughan TL: Interlaboratory reliability of microimmunofluorescence test for measurement of Chlamydia pneumoniae-specific immunoglobulin A and $\mathrm{G}$ antibody titers. Clin Diagn Lab Immunol 2004, 11:615-617.

53. Esteban A, Fernandez-Segoviano P, Frutos-Vivar F, Aramburu JA, Najera L, Ferguson ND, Alia I, Gordo F, Rios F: Comparison of clinical criteria for the acute respiratory distress syndrome with autopsy findings. Ann Intern Med 2004, 141:440-445.

doi:10.1186/cc11247

Cite this article as: Kojicic et al:: Risk factors for the development of acute lung injury in patients with infectious pneumonia. Critical Care 2012 16:R46.

\section{Submit your next manuscript to BioMed Central and take full advantage of:}

- Convenient online submission

- Thorough peer review

- No space constraints or color figure charges

- Immediate publication on acceptance

- Inclusion in PubMed, CAS, Scopus and Google Scholar

- Research which is freely available for redistribution

Submit your manuscript at www.biomedcentral.com/submit
C Biomed Central 